\title{
MAKING ALL THE DIFFERENCE: INCLUSION, EXCLUSION AND AMERICAN LAW by Martha Minow (Ithaca: Cornell University Press, 1990)
}

I.

Equality and the inclusion of all persons within the community lie at the heart of the general crisis of legitimacy of the liberal state.' In Western liberal democracies, the law's ability to deliver and promote equality remains one of the principal philosophical bases for our continued investment in its processes. Hence, any inability to deliver on the promise of equality provides a touchstone for justifying changes and departures from traditional tenets and approaches. The analysis of the phenomenon of difference recognizing, accommodating and expecting variety in human needs, desires and experiences - is one of the methods by which we attempt to understand the meaning and dimensions of equality and to implement it through legal and political action.

The scope and importance of the difference debate extends far beyond law. The recognition of "difference" or "subject position" and the role of the "other" as it affects both perspectives on knowledge and truth and the power to make them prevail in social relations permeate contemporary thought. Literary and political theory, psychoanalysis, philosophy and feminism are but a few of the most active sites. The difference debate potentially envisions no less than a restructuring of the normative principles in political and social discourse.

Among the central elements of this restructuring is a radical revisioning of our understanding of the human subject as a rational, free-standing, autonomous agent. This notion has traditionally undergirded the concept of free choice and made sensible the application of universal moral principles. Consideration of the construction of knowledge and the process by which it comes to be known as definitive of the truth is also central to the difference debate. Within this analysis of knowledge, the use of language is regarded as a critical force in the constitution of persons and social relations, as both the human subject and social relations are seen to contain an essential fluidity and indeterminacy which allow them to be continually remade. Language is then both a site and manifestation of power; the extent to which it either aids or constrains those who use it emerges as a recurring theme in the difference debate.

Martha Minow's Making All the Difference: Inclusion, Exclusion and American Law' is an attempt to both make sense of and offer solutions to the problem of difference in the legal sphere. As such it can be broadly placed among the diverse legal and political efforts to comprehend and come to terms with the disparity between liberalism's promise of inclusion and equality and the reality that certain groups and persons constantly come up short in the deal when liberal principles are applied to them.

1. Mark Tushnet suggests that this crisis of legitimacy is the impetus which is driving efforts to reconstruct liberal theory. See "The Possibilities of Interpretive Liberalism" (1991) 29 Alta. L. Rev. 276 at 277.

2. (Ithaca: Comell University Press, 1990). 
Within that category, Making All the Difference can be further grouped with attempts to rescue and preserve liberalism from its faults or deficiencies. It is part of what Robert Cover describes as the "recent explosion of legal scholarship placing interpretation at the crux of the enterprise of law.".3 Minow remains committed to the use of rights. However, she is an "interpretivist" to the extent that she too tries to extend and remake our understanding of them.

Minow considers the issue of equality by using the legal treatment of difference as a lens through which to reconsider traditional liberal approaches to rights. In particular, Minow focuses on the problems that result from two often-remarked shortcomings of liberalism. First, liberal principles have been developed and are applied without regard for the context in which conflicts or dilemmas arise. Second, liberal principles in their focus on the autonomous individual do not pay enough attention to the fact that persons exist in and are at least partly constituted by social relations.

Minow describes her book as an introduction to the legal treatment of difference. Although all of the material in the book is drawn from American history and case law, the relevance of the larger issue is not in any sense limited to that country; the same fundamental legal questions, accompanied by similar analyses, are engendering debate in most Western societies at this time.

Minow attempts to present the idea of difference as a broad unifying theme in a number of legal scenarios. At the outset, she frames the "difference dilemma" as follows: when does recognizing difference hinder or stigmatize people and when does treating people the same become insensitive to difference and hinder or stigmatize people on that basis? ${ }^{4}$ Unfortunately, we never really get an answer to this tantalizing question. Instead, Minow sidesteps a direct response to the framework she has conceived and concludes that the solution to the "difference dilemma" lies in "embedding rights in relationships." This involves neither a rejection of rights and rights discourse nor the retention of it in its classic form as the protection of individual autonomy.

Making All the Difference attempts to grapple with one of the most difficult and important contemporary legal issues. For that alone, Minow's work deservedly attracts attention. The connections she forges between the difference debate in law and the debate as it is playing out in other disciplines are both convincing and interesting and, more importantly, will be crucial to our developing understanding and resolution of the issues.

Throughout the book, Minow recounts engaging stories and sets valuable historical context to the dilemma; that is that context is useful particularly for what it has to teach us about how not to deal with difference. As well, the early part of the book functions as a useful guide to some important contemporary theoretical concepts. However, the work fails to deliver on its initial promise for a number of reasons, some of which relate

3. R. Cover, "Violence and the Word" (1986) 95 Yale Law Journal 1601.

4. Supra, note 2 at 20. 
to the structure and ordering of the material in the book and some of which go to the heart of her discussion of difference.

At the end of the book, we emerge without any convincing reason to be persuaded that Minow's particular characterization or conceptualization of the difference dilemma will advance the prospects of equality a great deal. Nor does Minow present any general criteria, caveats, or guidelines to help us decide when one of the two approaches to difference she has proposed - recognition or non-recognition - might be more appropriate or conducive to the true creation of equality than the other. This is by no means an easy task, perhaps it is even an enormous one, but it must surely be one of the goals of deciding to approach the difference dilemma from such a perspective. Furthermore, Minow, in endorsing certain philosophical precepts and developing a specific, oppositional conceptual framework to work with, sets the stage in the beginning of the book to suggest that she does in fact have such a goal. Hence when this project appears to be abandoned or at least avoided, we remain at the end still searching for some more revealing and constructive framework through which to consider the issue of difference.

In general, the rough proportion of raw material to analysis and discussion of the issue seems somewhat out of balance. Furthermore, the analysis which Minow does provide, rather than being persuasive, deep or progressively developed through the work, is often merely a restatement or illustration of the basic propositions that she presents at the outset.

In addition, the overall structure of the book is neither the most helpful one that could have been devised nor sufficiently defined and adhered to. This contributes to the perception that both the subject and its treatment are amorphous, difficult and unwieldy. Because it is undoubtedly true that the subject is inherently elusive, it seems crucial that Minow avoid the same problems in structuring her discussion and solutions.

Finally, there is an inherent dilemma in the whole difference project which Minow is, not surprisingly, unable to completely avoid and which is reflected in the sense of unfulfilled expectations that characterize Making All the Difference. The dilemma lies in recognizing difference and yet defining and applying structures to deal with it which must to some extent call on normative or universal principles. In a sense, this is the philosophical problem at the heart of the entire issue. In Making All the Difference, the tension between these two desires and the problems that can ensue while bringing them together are revealed most clearly in the discussion on rights as a solution to difference. Minow's attempt to both embrace difference and rescue and preserve a legal approach to conflict resolution which is predicated on universal norms at times requires unusual leaps of faith on the part of the reader and are, I think, ultimately unsatisfying.

II.

The work is broadly divided into three parts. Although not expressly presented as such, much of the book is comprised of material that Minow has previously published. Portions of her essays on rights for children, treatment of disabilities in schools and the history of progressive and reform movements in American law have been either reproduced intact or reworked and recast to lend themselves to a discussion on difference. 
Minow begins with a general discussion and orientation to the concept of difference and moves through its current treatment in such areas as psychology, anthropology and literary theory. Her brief survey of other disciplines reveals that the role of labelling as "different" is widely regarded as crucial across social science. Furthermore, much that is revealed in these other disciplines stands to be important and instructive to our understanding of how difference operates in law.

The principal thesis that emerges from the opening discussion is that difference, rather than being a quality that is intrinsic to some people or groups of people, is a product of relationships. That is to say, it is not identifiable as a thing in itself but only as a result of comparison. Moreover, difference, in the socially significant sense, is in fact a social construction as "difference is not discovered but humanly invented." ${ }^{.5}$ As an example, Minow cites Jewish racial identity which she regards as something that is socially constructed rather than scientifically verifiable. The creation of difference, therefore, is the process by which some distinctions between persons or groups come to matter and are invested with social and political value or importance. The dilemma that results is created by the fact that, although difference when viewed as a product of relationships is a trait common to us all, the burden of difference is shouldered disproportionately by certain members of society.

The corollary to this, which Minow does not explicitly acknowledge or explore to any degree in her analysis, is that these distinctions, in creating both normal and abnormal or exceptional people, also create a de facto social hierarchy.

The significance of this concept for legal purposes is obvious. The notion that equality means treating people in the same way without respect for personal differences is deeply ingrained at an ideological level in our legal culture. This remains so even as we are capable of acknowledging that gender or race differences, for example, often result in vastly disparate experiences within the legal system. As we are only beginning to explore the differential impact that the implementation of the "same treatment" concept has in practice, any movement toward expressly acknowledging and accommodating difference still runs headlong into the presumptions of neutrality, objectivity and universality that traditionally ground the application of legal principles. This in turn raises questions and concerns about importing an essential unfairness into the law when difference is recognized.

The most useful and successful part of the book is probably Minow's analysis of some of the traditional assumptions imbedded in law and legal decision-making that bear on the concept of difference. Minow has identified five assumptions that are problematic and which neatly encapsulate the obstacles that need to be overcome before law can successfully deal with the difference dilemma.

The first assumption, an inversion of Minow's own position that difference is a function of relationships, is that law regards difference as intrinsic rather than as the basis 
of comparison. The second problem, perhaps the most significant of the five elements, is the adoption of an unstated point of reference from which to assess difference. Minow here is utilizing insights that have been acquired in such fields as literary theory on the role of power and subject position in the construction of language and knowledge. She endorses the view that this referent is in fact not general or universal but particular. It only appears to be so because it is unstated and hence unseen; it only remains unstated because of the relative lack of power of those who are not within the prevailing norm. It is this referent for comparison which is central to both understanding and reconceiving equality.

Third, the judges and judging of difference are seen to be neutral. That is, there is no acknowledgement that either the persons judging operate from a particular "situated" perspective or that the judging process itself may possess an intrinsic and peculiar perspective. Fourth, Minow observes that law operates largely on the assumption that the views of the person judged are irrelevant.

Fifth, law assumes that the existing social arrangements are both natural and neutral. An intriguing but somewhat mystifying corollary to this assumption because as stated, it is neither necessarily obvious nor further explained in the book, is Minow's statement that law, therefore, views difference as a matter of personal choice.

From all of these observations, Minow concludes that, as differences are institutionally created, in order to get around the dilemma we need to focus on "what counts" as difference and investigate the social arrangements which make a particular trait matter in any given situation.

Difference as it relates to children and rights for children figures prominently throughout the book as Minow's earlier essays on children provide much of the factual foundation and illustration of the difference dilemma. ${ }^{6}$ For example, she locates the difficulty that we have in coming to terms with special educational programmes for deaf children in the fact that we presume it is normal to be able to hear. Treating the problem as residing in the difference of the deaf child from this norm means that the options are either: 1) segregating the child by providing the child with an environment in which he or she is "normal" or 2) integrating the child into the mainstream where the child is certain to be viewed as different. Minow's "rights in relationships" solution would regard everyone as both part of the problem and the solution: her suggestion is that everyone in the class could learn sign language. ${ }^{7}$

After laying this general groundwork, Minow moves into the second part of the book which is a review of past attempts to come to terms with differences. She classifies these attempts into three historical approaches: the "abnormal persons" approach, rights analysis

b. See for example "Are Rights Right for Children?" (1987) 1 American Bar Foundation Research Journal 203; "Beyond State Intervention in the Family: For Baby Jane Doe" (1985) 18 University of Michigan Journal of Law Reform 933; "Learning to Live with the Dilemma of Difference: Bilingual and Special Education" (1985) 48 Law and Contemporary Problems 157.

Supra, note 2 at $81-86$. 
and the "social relations" approach. Minow regards the last as the most fruitful, as even traditional rights analysis permits the replication of the distinction between normal and abnormal persons without dislodging the unstated norm from its role.

Minow's proposed social relations approach ultimately leads her to a survey of the various disciplines in which traditional canons of knowledge are or have been under attack. Beginning with the limiting and exclusionary nature of the social contract as conceived in liberal philosophy, she provides brief synopses of the relational aspects of such diverse topics as: legal process theory, law and economics, critical legal studies, the effect of labelling theory on psychology and sociology, structuralism in anthropology, object relations theory in psychoanalysis, literary theory and feminist scholarship. For her purposes, the common thread between these disciplines is that they all to a greater or lesser degree focus on the relationships between people, concepts and the observer and the observed. Of all the analyses proffered, she finds that feminism is the most congenial and accessible to relational thought because of its interdisciplinary focus and grounding in actual experience rather than abstract theory.

The third part of Minow's book is an attempt to reveal the social relations approach at work in law and draw some conclusions about the use of rights as a solution to the difference dilemma. After explaining the human cognitive need to categorize, simplify and thus resist all of the quite detailed and useful observations about how difference is created and functions, she launches into a further series of legal anecdotes. These seem intended to give more background and to illustrate largely by their presence how her thesis about difference operates in law, rather than to introduce anything new to the thesis that is developed to this point.

III.

Making All the Difference is useful for the general picture that it creates of the interrelatedness of much current social science work on the phenomenon of difference. Furthermore, to the reader who has had no introduction to some of the important contemporary concepts on the relations between power and knowledge, Minow's 5-point framework is a helpful orientation guide to keep in the foreground when considering judicial analysis of rights. The book, however, has a number of both technical and theoretical qualities which render the reading of the work as a whole a bit of a disappointment.

Firstly, it suffers to a degree from being cobbled together from parts of a number of previously written essays. This need not be fatal; however, in this case, the result is often a repetition of basic principles in different dress in various sections of the book. Minow has provided a great deal of interesting illustrative material. However, much of the material in the latter part of the book does not advance her basic proposition about the nature of difference in a forceful, clear or new enough way to warrant inclusion.

For this reason, the third part of the work is the most unsatisfying part of the work both from a theoretical standpoint and from a technical perspective. As Minow has surveyed the landscape from a number of vantage points and the book is already sufficiently full 
of examples to support the general problem she set out, the decision to broaden the field further at this point rather than get down more directly to analysis in a focused way seems simply distracting.

Because the work is presented as a freestanding treatise on difference rather than a collection of essays, the reader has an expectation of some fairly clear progression from theoretical groundwork through historical examples to analysis from which general principles or at least criteria for approaching difference can be drawn. Instead, in particular toward the end of the book, Minow mixes all three elements, backtracking over previously introduced material and digressing into a general discussion on law.

Minow's discussion on rights can be viewed as the theoretical culmination of the book. Therefore, her decision to follow those conclusions and discussions on general legal principles with more illustrations of difference in the field of medical treatment of disabled infants is mystifying. If it is critical to our understanding of difference, why has Minow not discussed it earlier? If it is not, why does it appear at this point?

Much of law lends itself to some consideration of the role of difference and norms. Hence, the inclusion of numerous case histories might be justified on one level. However, one is left wondering if, by including all of this material to illustrate the "difference dilemma," Minow was motivated more by a desire to include all of the work she has done in the field than to carefully build a picture of difference for the reader. If so, she should have simply published the essays with prefatory material and conclusions.

The consequence of this structure is that the architecture of the work is somewhat weak. Minow's hybrid approach, that is neither presenting the essays separately nor sufficiently integrating the material and discarding that which is not essential, wearies and ultimately distracts the reader from her arguments. While the book is rich in anecdotes and illustrations of the dilemma of difference, the material that joins, illuminates and analyzes in the end is disappointing. A tighter structure, more disciplined focus on the issue, as well as a better synthesis and editing of the material that was common to different sections would have been welcomed.

IV.

Making All the Difference can be frustrating from a theoretical standpoint due to Minow's diffusion of focus on the issue of difference. Moreover, it is less convincing than it might otherwise be because of the difficulty in determining where Minow herself stands on the two prongs of the difference dilemma she has set. We want to know why recognition of difference makes sense in some circumstances if not most, and if Minow stands by her thesis that an unstated norm is often or always operational in legal decisionmaking, then she should be able to tell us that it does.

While in the course of the book we are introduced to numerous examples of the difference dilemma as it confronts the courts, we receive only general admonitions by way of solutions. Minow states that we should treat difference as a function of relationships 
then compare the costs borne by different people. ${ }^{8}$ Yet it is not clear, at the end, that this broad prescription goes a great distance to solve the problem of the recognition or nonrecognition of difference. Furthermore, the impression remains that Minow herself is undecided about how to resolve the dilemma.

This reluctance to tackle the dilemma head on permeates the discussion. A significant number of statements are either phrased in a manner or placed in a context which renders both meaning and purpose ambiguous, either causing or resulting in lack of clarity. Minow can be curiously disengaged in her discussion. For example, she wonders "i[f $]$ a commitment to a norm of equality [is] advanced by accommodation" or if women are helped by "special benefits" in the workplace, later on stating that "these are knotty problems." This leaves the reader wondering whether her questions are "straw issues" or whether they are seriously up for grabs in her estimation.

The reading of the material is complicated from time to time by the difficulty in getting a solid fix on some of the core concepts that Minow employs. The net result is a certain instability at the centre of her thesis which adds to the uncertainty about precisely where she stands on some issues. For example, there appear to be several definitions of difference that operate in the book interchangeably and without warning. Although Minow describes difference as socially constructed at the outset, at other times she uses the word, as she must, in its more conventional meaning. At times it remains unclear or needlessly difficult to discern which meaning is in use. This makes the central problem, the disadvantage of difference, difficult to keep at centre stage. Minow states that, "even when well intentioned people ignore differences they reproduce them." 10 Is she here referring to differences that do in fact exist in some objective, essential sense? If so, it would be useful to distinguish between those that do exist and will continue to exist regardless and those that are socially constructed.

Is Minow in fact advocating the elimination of all socially recognized difference or just the disadvantage that results from it? While her general thesis would be consistent with the latter, at times her language is capable of suggesting the former. ${ }^{1 "}$ Perhaps a more differentiated treatment of difference itself would have assisted in resolving this ambiguity.

In her analysis, Minow does not broach the fact that one of the functions, as opposed to one of the consequences, of norms may be to ensure that some people bear the cost of the difference and others benefit. In other words, we may look at difference the wrong way for a reason.

Minow seems timid in coming to grips with the more malevolent aspects of differences and norms. In particular, Minow does not delve into the maintenance of norms as a

Supra, note 2 at 11.

Ibid. at 21.

Ibid. at 26.

See the note 60 on p. 68 at which she says that the "dilemma is whether to risk recreating the religious difference of disabled children by acknowledging it or by ignoring it." 
function of political power; instead she only tentatively allows that disparities in power may play a role in how the difference dilemma plays out and how effective rights are in any given situation. ${ }^{12}$ This caveat considerably understates the situation if it does not totally avoid the most pressing problem. This element is so crucial to both the comprehension and the solutions that any consideration of difference cannot persuade, if it does not thereby become irrelevant, as long as the role of power is not fully integrated into the equation.

\section{V.}

Minow's conclusions about the utility of rights discourse to solve the difference dilemma, particularly with respect to the meaning of rights discourse as a social practice, seem startlingly incongruous with the theoretical framework she has appeared to endorse in the earlier part of the book. As a consequence, the reader is left with the impression that we have unexpectedly arrived at an unforeseen destination at the last minute; furthermore, we are wondering how this particular train got us there.

Part of the lack of success with the last part of the book is the largely unexamined and unexplained correlation between the difference dilemma as she has set it out and the use of rights as a solution. The lack of serious consideration of the shortcomings of rights seems critical. For most persons who are considering how to deal with the differential effect of law on the classes of persons outside the operational norm that Minow has identified whether or not, or at least how and when, to employ the concept of rights is a crucial issue. ${ }^{13}$ In accepting the view of rights that she does, Minow enters the debate past the point that could be regarded as the most problematic.

Some of Minow's propositions about the function and effect of rights strain the reader's credulity. For example, Minow states that a rights claim automatically creates a connection to others because, whether the claim is accepted or rejected, it articulates a boundary. ${ }^{14}$ By this definition, all rights implicate others. While this is true in a sense, it seems equally true that rights, especially negative rights, individuate. Therefore, it seems an unwarranted leap to then conclude that all assertions of autonomy from constraints are in fact really a mode of experiencing connection to others.

Minow extols in a quite dramatic fashion the qualities of a community committed to rights. She states that the use of rights discourse affirms community, and, furthermore, that it affirms a particular kind of community, one that is committed to allowing suppressed points of view to be heard. ${ }^{15}$ From there she continues, "committed to making a rhetoric of rights available where it has not been heard before" that community then uses rights to make conflict audible. ${ }^{16}$

Supra, note 2 at 298.

See for example C. Smart, The Power of Law (1989), E. Kingdom, What's Wrong With Rights (1991) and M. Tushnet, "An Essay on Rights" (1984) 62 Texas L. Rev. 1363.

Supra, note 2 at 302.

Supra, note 2 at 299.

Ibid. 
There appears to be a tautology in this description of how rights function. Apart from that, it is not at all obvious how she gets from the first statement to the last in such short order. How does it necessarily follow that the mere use of rights in a community translates into a commitment by that community to using them in new and innovative ways that diverge from the principles or concerns that originally gave rise to them? There seems to be at least as much evidence of non-observance as observance of such a practice. As the proposition seems far from self-evident, more discussion seems in order for this proposition to be both raised and accepted.

Nor is it obvious that the mere employment of rights discourse implies the commitment to enable suppressed points of view to be heard as Minow suggests. ${ }^{17}$ In fact, a common complaint raised about rights discourse is that it requires that points of view be fashioned and presented in a certain manner. The net result is that some claims or harms may not be adequately represented at all within the existing framework while competing activities may benefit or rise in the public estimation upon being cloaked in the mantle of rights. This is such an oft-repeated contention at this stage in the debate that it seems that she does without addressing the effect of rights characterization on claims.

As Minow herself notes, quoting Carol Gilligan, "If you have power, you can opt not to listen. And you do so with impunity." ${ }^{18}$ Therefore, when Minow states that the use of rights equals a commitment to a community in which all views will be listened to, this seems to be a point that must be dealt with in some depth if her particular defence of rights is to stand. It would be less contentious, for instance, if Minow had limited herself to simply saying that the employment of rights allows certain types of parallel claims to be heard.

Rights may not imply any such commitment on the part of any given user. The discourse may be used simply because it is the linguistic currency in circulation. Moreover, it can be used tactically, deliberately, to construct a position of advantage in the legal arena and to cast claims in a light of legitimacy. Therefore, it seems naive to characterize the use of rights as inevitably an invitation to the opposite side to engage in a exercise in community relations.

Minow early on discusses the role of power in the construction and control of language and endorses the view that this is a crucial part of the creation of difference and norms. We, therefore, come to expect that this position will inform with equal force her conclusions about rights as the solution to this dilemma. But Minow, after allowing that power plays a role in which claims persuade, merely says that "these are difficult and persistent questions in a community committed to rights discourse."19

Ultimately Minow's avoidance of a direct and detailed analysis of the social meaning of difference as hierarchy leads us to be unsure whether she concludes that the problem is the perpetuation of difference or the powerlessness flowing from that difference. More 
critical treatment of this crucial issue would have focused the discussion on the specifically harmful aspects of the traditional notion of difference and removed much of the ambiguity which clouds the book.

Kerry Rittich, LL.B.

University of Alberta 